\title{
Radioimmunoassay of Chromogranin A and Free Metanephrines in Diagnosis of Pheochromocytoma
}

\author{
R. BÍLEK ${ }^{1}$, T. ZELINKA ${ }^{2}$, P. VLČEK ${ }^{3}, J_{\text {. DUŠKOVÁ }}^{4}$, D. MICHALSKÝ ${ }^{5}$, K. NOVÁK ${ }^{6}$, \\ E. VÁCLAVÍKOVÁ ${ }^{1}$, J. WIDIMSKÝ Jr. ${ }^{2}$
}

${ }^{1}$ Institute of Endocrinology, Prague, Czech Republic, ${ }^{2}$ Center for Hypertension, Third Medical Department - Department of Endocrinology and Metabolism, First Faculty of Medicine, Charles University and General University Hospital, Prague, Czech Republic, ${ }^{3}$ Department of Nuclear Medicine and Endocrinology, Faculty Hospital Motol and Second Faculty of Medicine, Charles University, Prague, Czech Republic, ${ }^{4}$ Institute of Pathology, First Faculty of Medicine, Charles University and General University Hospital, Prague, Czech Republic, ${ }^{5}$ First Department of Surgery - Department of Abdominal, Thoracic Surgery and Traumatology, First Faculty of Medicine, Charles University and General University Hospital, Prague, Czech Republic, ${ }^{6}$ Department of Urology, First Faculty of Medicine, Charles University and General University Hospital, Prague, Czech Republic

Received January 17, 2017

Accepted April 28, 2017

\section{Summary}

This work discusses the clinical performance of chromogranin A, free metanephrine and normetanephrine determination in plasma using a radioimmunoanalytical methods for the diagnosis of pheochromocytoma and paraganglioma. Blood samples were collected from 55 patients (46 pheochromocytomas, 9 paragangliomas). A sampling of biological materials was performed preoperatively and about one week, six months and one year after adrenal gland surgery. The comparative group without a diagnosis of pheochromocytoma/paraganglioma consisted of 36 pheochromocytoma/paraganglioma patients more than 4 months after adrenal gland surgery, and of 87 patients, 16 of them with multiple endocrine neoplasia, 9 with medullary and 5 with parafolicullar carcinoma of the thyroid gland. The rest were patients with various adrenal gland disorders. Chromogranin A, metanephrine and normetanephrine were determined in the EDTA-plasma using a radioimmunoassay kits Cisbio Bioassays, France and IBL International $\mathrm{GmbH}$, Germany. Clinical sensitivity was $96 \%$ for the combination of metanephrine and normetanephrine, and $93 \%$ for chromogranin A. Clinical specificity was $100 \%$ for the combination metanephrine and normetanephrine, and $96 \%$ for chromogranin A. Falsely elevated levels of chromogranin A were observed in 1 patient with chronic renal insufficiency and 9 analyses were influenced by the administration of proton pump inhibitors. These results were excluded of CGA specificity. Both the combination of plasma free metanephrine, normetanephrine and chromogranin $A$ as determined by radioimmunoassays, which are simple without the necessity of special laboratory material, are effective markers of pheochromocytoma or paraganglioma. Chromogranin A exerts association to malignity and all markers are associated with tumor mass.

\section{Key words}

Chromogranin A - Plasma free metanephrine - Plasma free normetanephrine - Radioimmunoassay • Pheochromocytoma • Paraganglioma

\section{Corresponding author}

R. Bilek, Institute of Endocrinology, Narodni 8, 11694 Prague 1, Czech Republic. Fax: +420 224905325. E-mail: rbilek@endo.cz

\section{Introduction}

Pheochromocytoma (PHEO) or paraganglioma (PGL) are rare tumors associated with neuroendocrine chromaffin cells usually found in the adrenal medulla and other ganglia of the nervous system (Tischler 2006). 
PHEO is a tumor arising from adrenomedullary chromaffin cells that commonly produces catecholamines. PGL is a tumor derived from extraadrenal chromaffin cells of the sympathetic paravertebral ganglia (thorax, abdomen, pelvis) producing catecholamines or parasympathetic ganglia located in the neck and at the base of the skull, which do not produce catecholamines (Lenders et al. 2014). The adrenal tumor localization is usually found in $80-85 \%$ of patients, and extra-adrenal sympathetic and parasympathetic PGL are observed in 10-20\% patients (Chen et al. 2010, van Berkel et al. 2014). In this study we have used PPGL as a general term for both PHEO and PGL. Approximately $10 \%$ of the PHEOs and $20 \%$ of the PGLs are malignant with poor survival (Andersen et al. 2011). Up to $30 \%$ of PPGL patients have recognizable germline mutations including multiple endocrine neoplasia type 2A (MEN2A) or 2B (MEN2B), von Recklinghausen neurofibromatosis type 1 (NF1), von Hippel-Lindau syndrome (VHL), and succinate dehydrogenase complex - subunits A, B, C, D (SDHx) syndrome (Mazzaglia 2012). Since 1990, 14 different PPGL susceptibility genes have been reported (Lenders et al. 2014). Mainly mutations in the tumor suppressor gene Von Hippel-Lindau ( $V H L)$ and the mitochondrial succinate dehydrogenase enzyme complex subunit B $(S D H B)$ are associated with malignancy (Andersen et al. 2011).

The genetic syndromes commonly associated with PPGLs are based on the extra-adrenal PGLs with noradrenergic phenotype of VHL and SDHx. The biosynthesis of the enzyme phenylethanolamine-Nmethyltransferase converting norepinephrine to epinephrine is downregulated at both mRNA and protein level in sympathetic or parasympathetic paragangliomas (Grouzmann et al. 2015). Increased production of norepinephrine results in an elevated concentration of normetanephrine (NMN) in circulation. The epinephrine and metanephrine $(\mathrm{MN})$ are usually within the normal reference range. The adrenal adrenergic phenotype is characteristic for MEN2A, MEN2B and for NF1. This phenotype is typical with an elevated concentration of epinephrine and secondary metanephrine with varying amounts of norepinephrine and normetanephrine in the circulation (Lenders et al. 2014, van Berkel et al. 2014). A lack of catechol O-methyltransferase in sympathetic nerves, the major site of initial norepinephrine metabolism, means that the O-methylated metabolites are relatively specific markers of chromaffin tumors. These metabolites are produced continuously within tumors by a process that is independent of exocytotic catecholamine release, which for some tumors occurs at low rates or is episodic in nature (Lenders et al. 2014). In addition $70 \%$ of patients with SDHB and SDHD mutations increase methoxytyramine (dopamine) production (Eisenhofer et al. 2011) due to the absence of tyrosine hydroxylase, the enzyme that catalyses the initial and rate-limiting step in catecholamine biosynthesis (van Berkel et al. 2014). Dopaminergic phenotype can be a good indicator of metastatic disease (Eisenhofer et al. 2012, Fliedner et al. 2010). Sympathetic PPGL usually produce significant amounts of catecholamines, whereas parasympathetic PGL can be endocrinologically inactive (Lenders et al. 2005).

Medullary thyroid cancer (MTC) associated with RET proto-oncogene mutations is a malignancy of the thyroid $\mathrm{C}$ cells which can elaborate a number of peptides and hormones, such as calcitonin, carcinoembryonic antigen, and chromogranin A (Busnardo et al. 2006). Some or all of these markers are elevated in patients with MTC and can be used to confirm the diagnosis as well as to follow patients longitudinally for recurrence (Chen et al. 2010).

Chromogranins belong to the family of secretory chromogranin and secretogranin proteins. They are found in secretory vesicles throughout the neuroendocrine system where chromogranin A (CGA) is the main component (d'Herbomez et al. 2010). CGA is the major soluble acidic protein with a molecular weight of $48 \mathrm{kDa}$ (439 amino acids) co-stored and co-released with catecholamines, and can function as a pro-hormone by giving rise to several bioactive peptides (D'Amico et al. 2014). This protein is the driving force for the biogenesis of secretory chromaffin granules present in the diffuse neuroendocrine system (D'Amico et al. 2014). High levels of CGA, co-stored and co-secreted with catecholamines, may indicate tumor mass and malignancy in PPGL patients and can be used to monitor response and relapse (Andersen et al. 2011). CGA is also a valuable complementary biomarker of SDHB-related PPGL. Although non-specific for PPGL, CGA may facilitate diagnostic evaluation of SDHB-related PPGL, especially where the measurement of plasma metanephrines could otherwise be delayed by decreased availability or cost restriction (Zuber et al. 2014). High levels of CGA at the time of PPGL diagnosis were associated with the presence of metastases according to the histological evaluation of primary PPGL tumors with 
PASS scoring scale (Thompson 2002), which is in most cases above four (Szalat et al. 2011). A value less than 4 out of 20 points supports the benign character of the tumor (Thompson 2002).

CGA was significantly higher in patients affected by hepatocellular carcinoma (Malaguarnera et al. 2010), gastroenteropancreatic neuroendocrine tumors (Lawrence et al. 2011), and in primary and metastatic small intestinal neuroendocrine tumors (Giovinazzo et al. 2013). Its concentration in circulation is also increased after myocardial infarction, acute coronary syndrome and heart failure (Estensen et al. 2006, Jansson et al. 2009). The cardiovascular complications were observed in nearly $20 \%$ of patients with PPGLs due to increased level of catecholamines (Zelinka et al. 2012). Problems were observed with falsely elevated CGA levels in patients treated with proton pump inhibitors (Korse et al. 2011). This effect of proton pump inhibitors (PPI) is fully eliminated after discontinuation of PPI for 2 weeks (Mosli et al. 2012). Also chronic renal insufficiency can substantially increase the concentration of circulated CGA (O'Connor et al. 1989).

ROC analysis revealed a threshold of $215 \mu \mathrm{g} / 1$ for chromogranin A with rather low sensitivity (73.9\%) and specificity $(74.2 \%)$ in comparison with plasma metanephrines. A weak positive correlation was found between the tumor size of pheochromocytomas and plasma metanephrine $(\mathrm{r}=0.53, \mathrm{p} \leq 0.05)$ as well as chromogranin A ( $\mathrm{r}=0.60, \mathrm{p} \leq 0.01)$ (Unger et al. 2012).

High diagnostic sensitivity of plasma normetanephrine, metanephrine and methoxytyramine for the detection of PPGL can only be guaranteed using upper cut-offs of reference intervals established with blood sampling under supine fasting conditions (Darr et al. 2014). Plasma free normetanephrine levels are influenced by age and age-adjusted cut-off values improve diagnostic performance (Eisenhofer et al. 2013, Eisenhofer and Peitzsch 2014). Several pre-analytical factors, such as exercise, posture, food with substantial quantities of biogenic amines, stress, hypoglycemia and medications may affect test results (van Berkel et al. 2014).

The Endocrine Society (Lenders et al. 2014) recommends that initial screening for PPGLs include measurements of plasma free metanephrines or urine fractionated metanephrines using liquid chromatography with mass spectrometric or electrochemical detection methods. Liquid chromatography with tandem mass spectrometry (LC-MS/MS) offers numerous advantages over other analytical methods and is the method of choice when measurements include methoxytyramine (Eisenhofer and Peitzsch 2014). LC-MS/MS limit of quantification under $75 \mathrm{pmol} / \mathrm{l}$ was achieved for $\mathrm{MN}$, NMN and 3-methoxytyramine using only $150 \mu \mathrm{l}$ of plasma samples (Adaway et al. 2015).

The plasma test offers advantages over the urine test, although it is rarely implemented correctly, rendering the urine test preferable for mainstream use (Eisenhofer and Peitzsch 2014). The comparison of results for determination of plasma normetanephrine and metanephrine between LC-MS/MS and enzyme-linked immunoassay (EIA) in diagnosis of PPGLs was unfavorable to the EIA method where the underestimation of $\mathrm{MN}$ and NMN was observed (Weismann et al. 2015). On the other hand, published studies show that plasma free and urinary metanephrines measured by enzyme immunoassays are convenient and reliable parameters for the diagnosis of pheochromocytoma (Brain et al. 2006, Pamporaki et al. 2013, Unger et al. 2012). In a group of 63 patients with histologically-proven pheochromocytoma (52 PHEO and 14 PGL, 14 of the patients had a family history of the disease), a CGA assay was highly efficient in diagnosing pheochromocytomas in the absence of renal insufficiency (d'Herbomez et al. 2007). A significant positive relationship was demonstrated between tumor mass and serum CGA levels (Bilek et al. 2008, d'Herbomez et al. 2001, Giovanella et al. 2006). Measurement of plasma free $\mathrm{MN}$ and NMN by radioimmunoassay represents an effective alternative to chromatographic determinations with electrochemical or mass spectrometric detection methods. There was found the clinical sensitivity $100 \%$ and specificity $95 \%$ of combined NM and NMN determined by radioimmunoassay in plasma (Pussard et al. 2014).

In this study we presented our experiences with radioimmunoanalytical determination of plasma CGA, MN, NMN in groups of patients who suffered of PPGLs. Patients with various endocrine disorders other than PPGLs were used as the comparative group.

\section{Materials and Methods}

\section{The group of patients}

Included in the study were the group of PPGL patients and the comparative group of patients without diagnosis of PPGL. Patients with pheochromocytoma or paraganglioma consisted of 55 patients aged $51 \pm 18$ 
(18-78) years, 26 females aged $56 \pm 18$ (18-78) years, 29 males aged $47 \pm 16(20-76)$ years. Pheochromocytoma occurred in 46 patients, paraganglioma in 9 patients. Adrenergic phenotype of disease was observed in 30 patients (4 MEN2A+MTC, 1 MEN2B+MTC, 2 NF1, 23 PHEO), noradrenergic phenotype was found in 25 patients (13 PHEO, 8 PGL, 1 SDHD, 3 VHL).

A sampling of biological materials was performed preoperatively and about one week, six months and one year after surgery. A blood basal sampling was performed $20 \mathrm{~min}$ after the introduction of cannula in supine position. All four collections were conducted in 28 patients (21 PHEO, 1 PGL, 2 NF1, 2 VHL, 1 SDHD, 1 MEN2A+MTC), 3 collections in 8 patients (6 PHEO, 1 PGL, 1 VHL), 2 collections in 6 patients (6 PHEO), and 1 collection taking before surgery was conducted in 13 patients (5 PHEO, 3 PGL, 4 PGL, 1 MEN2B+MTC).

The comparative group consisted of 36 PHEO or PGL patients more than 4 months after adrenalectomy (27 PHEO, 2 PGL, 2 NF1, 3 VHL, 1 SDHD, 1 MEN2A+MTC) and of 87 patients aged $52 \pm 19(7-84)$ years, 56 females and 31 males without diagnosis of PHEO or PGL (2 MEN2A, 9 MEN2A+MTC, 1 MEN2B, 2 MEN2B+MTC, 9 MTC, 5 with parafollicular carcinoma of the thyroid gland, 8 with secondary hypertension, 20 with adrenal adenoma, 4 with adrenal hyperplasia, 15 with adrenal tumors and 12 patients were without diagnosis).

The investigation was approved by the local Ethical Committee.

\section{Laboratory examination}

CGA, MN, and NMN were determined in the EDTA-plasma using a commercially available radioimmunoassay kits. For CGA, a solid-phase two-site immunoradiometric assay was used with primary immobilized monoclonal antibodies and secondary radioiodinated monoclonal antibodies, both directed against sterically remote sites on the CGA molecule (manufacturer Cisbio Bioassays, Codolet, France; code CGA-RIACT). MN and NMN were determined using MetCombi Plasma RIA kit (manufacturer IBL International GmbH, Hamburg, Germany, code RE29111) for quantitative determination of free metanephrine and normetanephrine in human plasma by competitive radioimmunoassay.

\section{Statistics, calculations and modeling}

All statistical calculations were made using the computer program NCSS 2004 (Number Cruncher Statistical Systems, Kayville, Utah, USA). The individual points in the time series of the CGA, MN, and NMN examination were interpolated after inverse or logarithmic transformation by the Newton polynomial (Greenbaum and Chartier 2012) programmed up to the $12^{\text {th }}$ degree using our own program working in Lotus 1-2-3 of the IBM Corporation, USA. Individual curves were counted for all patients with 3 and 4 determinations of CGA, MN, and NMN during more than the annual monitoring of their condition. These curves along with specific values of MN, NMN and CGA are shown in Figures 1, 2 and 3. For all patients diagnosed with PPGL, the nature of the illness was differentiated in the Figures by solid symbols given in the legend of the Figures. These were patients suffering from PHEO, PGL, SDHD, NF1, VHL, MEN2A with MTC and MEN2B syndromes. Special "empty" symbols were used for patients administered proton pump inhibitors and the same "empty" symbols were used to distinguish 1 patient suffering from chronic renal insufficiency. The curves were modeled so that the concentrations of monitored analytes before the operation were transferred to the $\mathrm{Y}$ axis to the 0 time corresponding to the operation on the adrenal gland. The reference range is defined by a transparent rectangle on the curves. The course of the curves in a given reference range was recorded in the part of the Figures labeled with the letter B. The clinical sensitivity of the individual tests for determining $\mathrm{MN}$, NMN and CGA is well evident in this part. The mean curve of the individual analytes consists of patient values for whom concentrations at time 0 were greater than the cut-off value for MN, NMN or CGA is depicted on the Figures in part C. A dashed curve shown here consists of the mean curve to which twice the value of the standard deviation was added. This curve tells us with $95 \%$ probability when the concentration of the individual analytes will return to the normal reference range following the operation.

\section{Results}

Figure 1 describes the changes in $\mathrm{MN}$ concentration in a given time period. It is evident from Figures $1 \mathrm{~A}$ and $1 \mathrm{~B}$ that the clinical sensitivity is relatively low for patients with PPGL (55\%), while it is evident from Figure $1 \mathrm{~A}$ that the clinical specificity is $100 \%$ and 
Figure $1 \mathrm{C}$ shows that a sufficient reserve exists for the reference range with the cut-off value $<100 \mathrm{ng} / \mathrm{l}$. MN returns to a normal reference range in an average of 2.5 weeks (Fig. 1C).

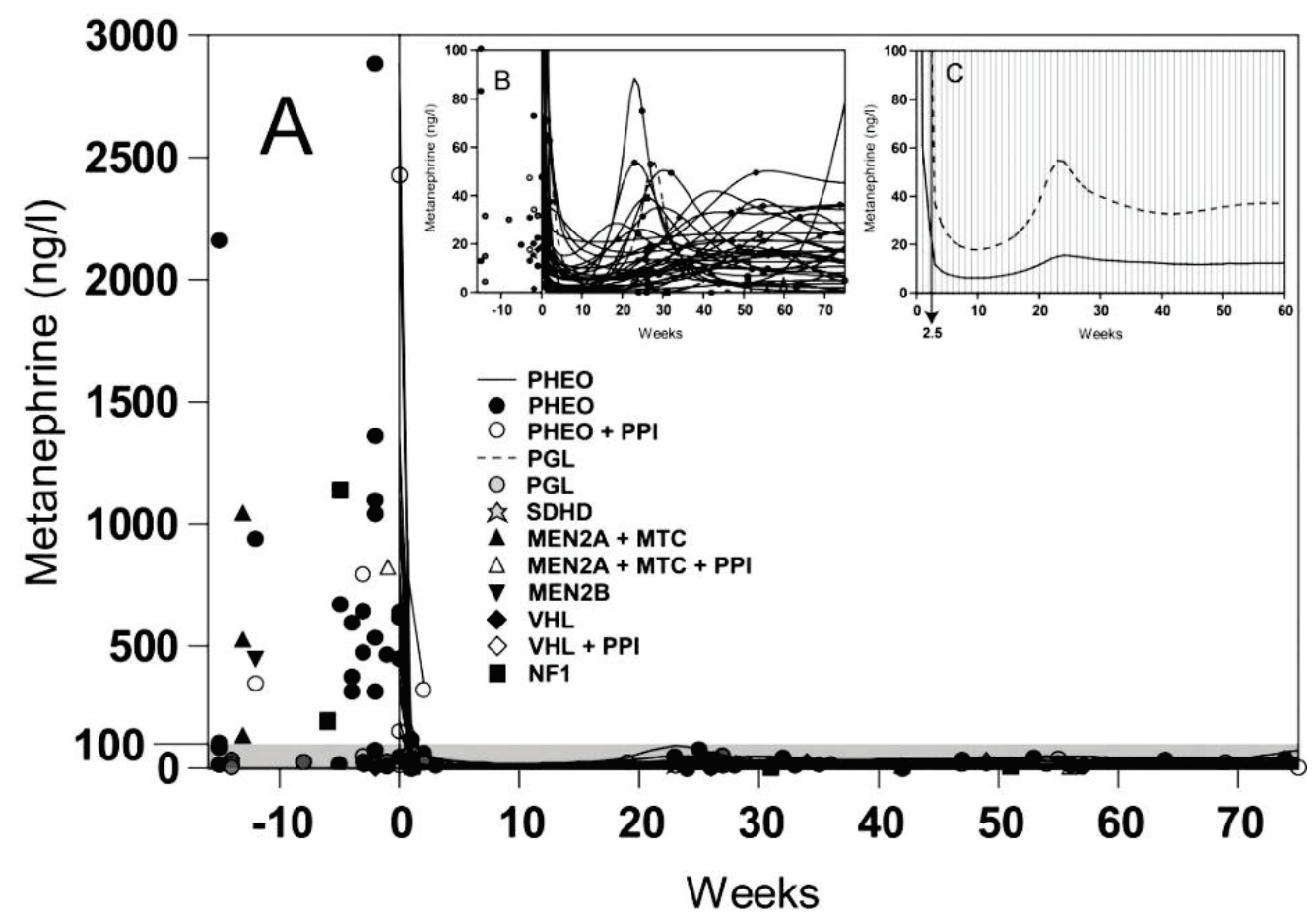

Fig. 1. Part $\mathbf{A}$ shows the results of determining metanephrine (MN) with specific values determined before the operation and after the operation using symbols describing the type of syndrome of pheochromocytoma (PHEO) or paraganglioma (PGL) patients. The values are linked by the curves calculated using a Newton polynomial of the $12^{\text {th }}$ degree and a transparent rectangle indicates the reference range. The values and curves in part $\mathbf{B}$ correspond to the given reference range. The mean MN curve taken from patient values for which concentrations at time 0 were greater than the cut-off value for MN is depicted in part $\mathbf{C}$. A dashed curve shown here consists of the mean curve to which twice the value of the standard deviation was added. Abbreviations: pheochromocytoma (PHEO), paraganglioma (PGL), multiple endocrine neoplasia (MEN), medullary thyroid cancer (MTC), von Recklinghausen neurofibromatosis type 1 (NF1), von Hippel-Lindau syndrome (VHL), succinate dehydrogenase complex - subunit D syndrome (SDHD), and patients treated with proton pump inhibitors (PPI).

Figure 2 describes changes in NMN concentration in a given time period. It is evident from Figures $2 \mathrm{~A}$ and $2 \mathrm{~B}$ that clinical sensitivity reaches $80 \%$ in PPGL patients and is thus higher than the clinical sensitivity for $\mathrm{MN}$. As with $\mathrm{MN}$, clinical specificity reached $100 \%$ (Fig. 2A) and NMN returned to a reference interval with a cut-off value of $170 \mathrm{ng} / \mathrm{l}$ in 1.5 weeks on average.

Figure 3 describes changes in CGA concentration in a given time period. It is evident from Figures $3 \mathrm{~A}$ and $3 \mathrm{~B}$ that clinical sensitivity reaches $93 \%$, which is higher than $\mathrm{MN}$ or $\mathrm{NMN}$, but the combined sensitivity of $\mathrm{MN}$ and NMN corresponds to a value of $96 \%$ and is thus higher in the given PPGL group than in the case of CGA. As seen in Figure $3 \mathrm{~A}$, the clinical specificity was considerably influenced by administering proton pump inhibitors and in one case by chronic renal insufficiency. These results were not included in the clinical specificity calculation since such increased values can be normalized by not administering PPI to patients, or long-term kidney failure must be taken into consideration when interpreting the results as the case may be. Clinical specificity was in this case equal to $98 \%$ with CGA. CGA returned to the normal reference range in average within 2.7 weeks.

All results concerning clinical sensitivity in patients with a PPGL diagnosis, measured before the adrenal gland operation, are shown in Table 1. Patients are divided into adrenergic and noradrenergic phenotypes and both cut-off values for MN, NMN, CGA and their mean values, standard deviations, ranges of measured concentration in plasma and the number of PPGL patients diagnosed with a specific disease syndrome are given here. In summary, it can be stated that clinical sensitivity had a value of $55 \%$ for MN, $80 \%$ for NMN, $96 \%$ for a combination of $\mathrm{MN}+\mathrm{NMN}$ and $93 \%$ for CGA. The test for $\mathrm{MN}$ failed for the noradrenergic phenotype of patients; the test for NMN failed in several cases of the 
adrenergic phenotype of patients with diagnosed PHEO $(n=6)$, the noradrenergic phenotype of PGL $(n=2)$, and in one case of the syndromes NF1, MEN2A+MTC, MEN2B+MTC with the adrenergic phenotype. Clinical sensitivity for CGA had a value of $93 \%$ and the test failed in 2 cases of adrenergic phenotype PHEO and in 2 cases of noradrenergic phenotype patients with VHL and PGL syndrome. One patient with a noradrenergic phenotype of PGL had 27 weeks after the operation a CGA value in plasma of $227 \mu \mathrm{g} / 1$ and was diagnosed with developing PHEO. MN and NMN values were in the reference range in this patient, so that in reality the CGA value was correct, but the MN and NMN values did not react to the development of PHEO.

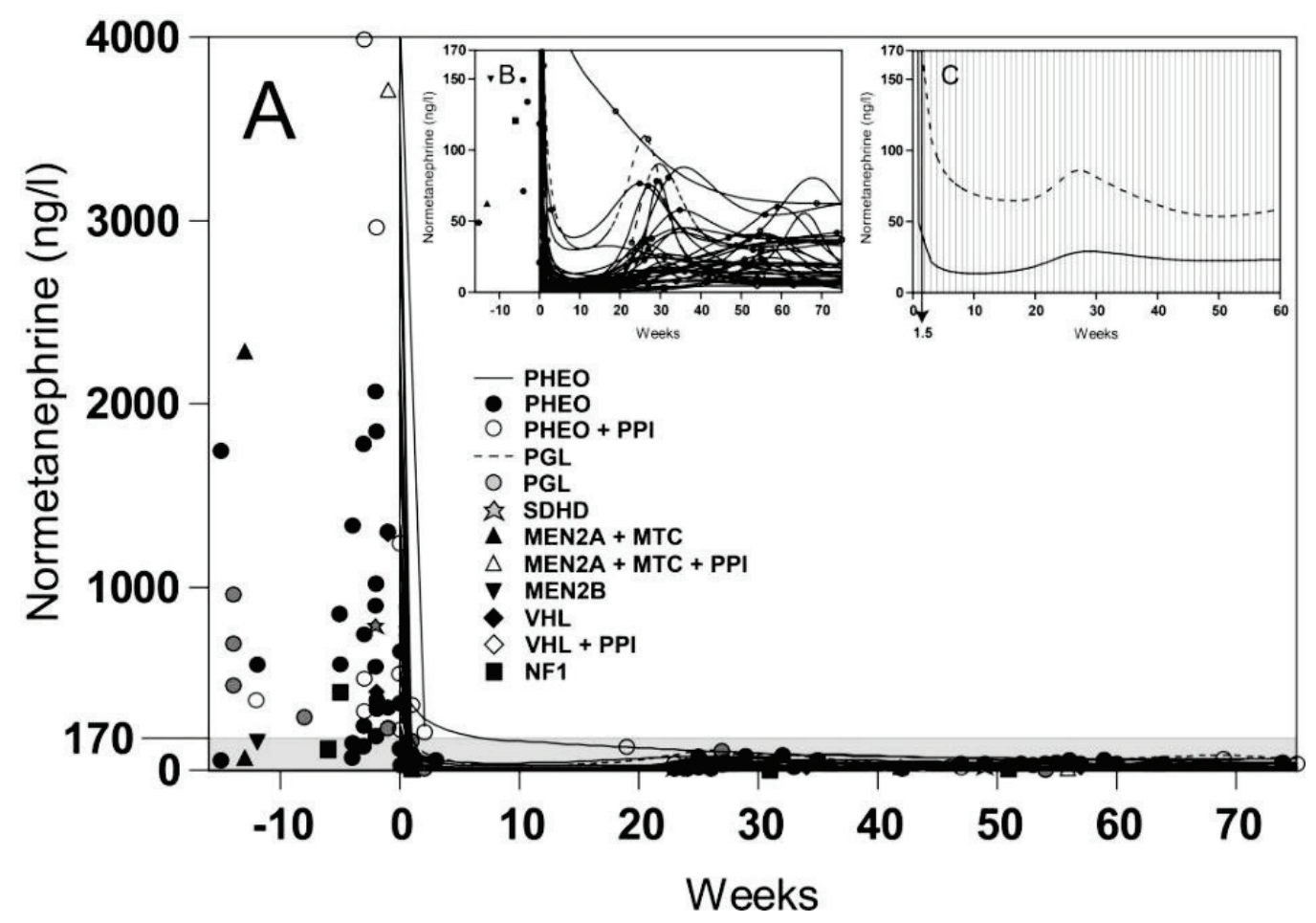

Fig. 2. Part A shows the results of determining normetanephrine (NMN) with specific values determined before the operation and after the operation using symbols describing the type of syndrome of pheochromocytoma (PHEO) or paraganglioma (PGL) patients. The values are linked by the curves calculated using a Newton polynomial of the $12^{\text {th }}$ degree and a transparent rectangle indicates the reference range. The values and curves in part $\mathbf{B}$ correspond to the given reference range. The mean NMN curve taken from patient values for which concentrations at time 0 were greater than the cut-off value for NMN is depicted in part $\mathbf{C}$. A dashed curve shown here consists of the mean curve to which twice the value of the standard deviation was added. Abbreviations: pheochromocytoma (PHEO), paraganglioma (PGL), multiple endocrine neoplasia (MEN), medullary thyroid cancer (MTC), von Recklinghausen neurofibromatosis type 1 (NF1), von Hippel-Lindau syndrome (VHL), succinate dehydrogenase complex - subunit D syndrome (SDHD), and patients treated with proton pump inhibitors (PPI).

Table 2 gives all results concerning clinical specificity for both PPGL patients with MN, NMN and CGA values that were included in calculations only in the case that they were determined at least 4 months following the adrenal gland operation and their values were within the normal reference ranges. Table 2 also included results from a comparative group in which no case of PHEO or PGL was diagnosed, although some of these patients had a diagnosis closely related to PPGL. This concerned patients with MEN2A syndrome or MEN2B with MTC or without it, or merely somatic MTC. Patients with parafollicular thyroid carcinoma, with hyperplasia, adenoma or adrenal tumors, with secondary hypertension and, in 12 cases, undiagnosed patients were also included in the group. This concerned a total of 151 analyses.

Table 2 gives both cut-off values for MN, NMN, CGA and their mean values, standard deviations, ranges of measured concentration in plasma and the number of PPGL patients diagnose. Clinical specificity has a value of $100 \%$ for $\mathrm{MN}, 99 \%$ for $\mathrm{NMN}, 100 \%$ for a combination of MN/NMN and $96 \%$ for CGA. Clinical specificity was $100 \%$ successful for $\mathrm{MN}$; in the case of $\mathrm{NMN}$, the test failed for 1 patient with a diagnosis of MTC without the presence of PHEO; in the case of CGA, the test failed for 4 patients with adrenal tumors, and with 1 patient with adrenal adenoma and 1 patient with adrenal hyperplasia. 


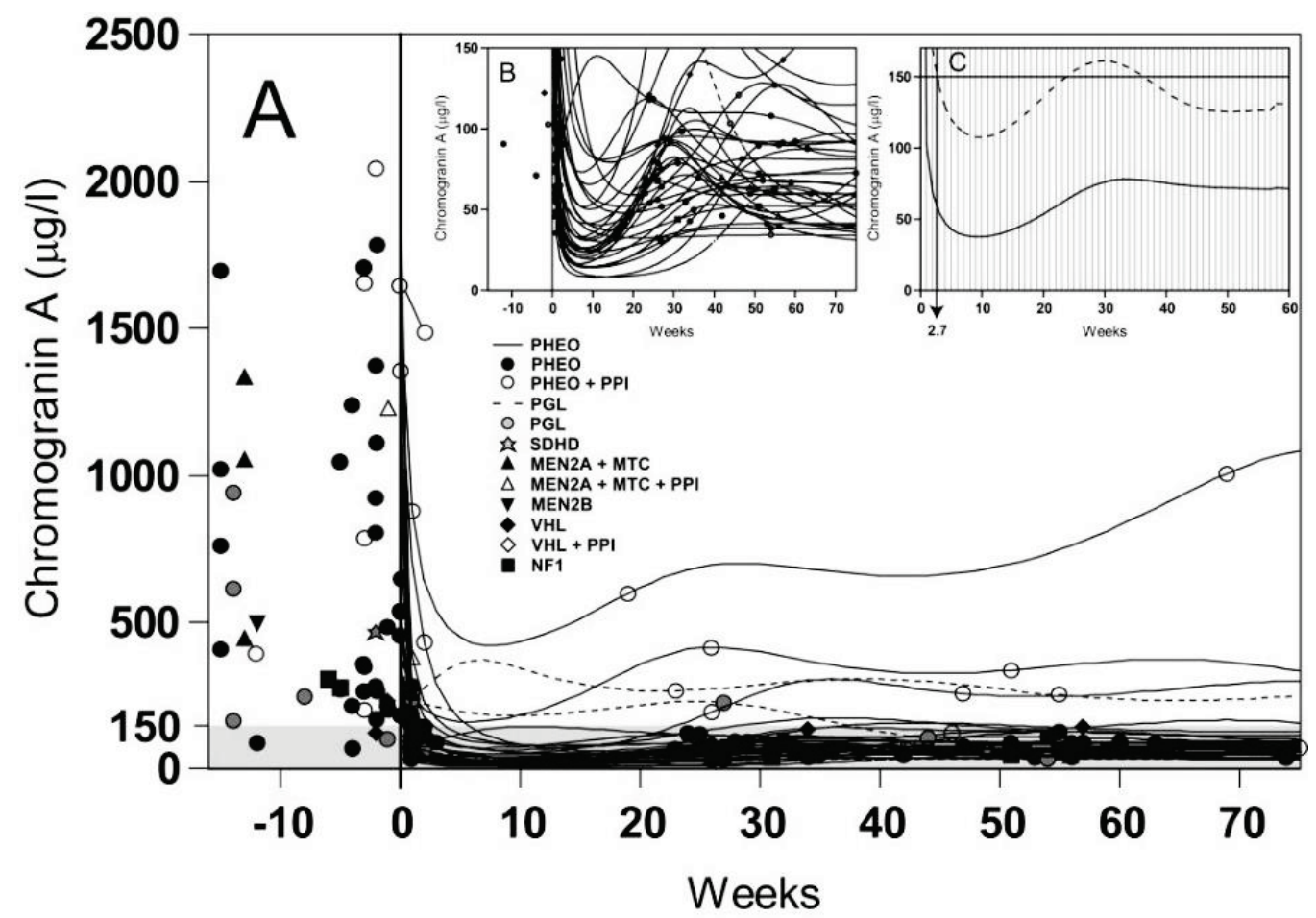

Fig. 3. Part A shows the results of determining chromogranin A (CGA) with specific values determined before the operation and after the operation using symbols describing the type of syndrome of PPGL patients. The values are linked by the curves calculated using a Newton polynomial of the $12^{\text {th }}$ degree and a transparent rectangle indicates the reference range. The values and curves in part B correspond to the given reference range. The mean CGA curve taken from patient values for which concentrations at time 0 were greater than the cut-off value for MN is depicted in part $\mathbf{C}$. A dashed curve shown here consists of the mean curve to which twice the value of the standard deviation was added. Abbreviations: pheochromocytoma (PHEO), paraganglioma (PGL), multiple endocrine neoplasia (MEN), medullary thyroid cancer (MTC), von Recklinghausen neurofibromatosis type 1 (NF1), von Hippel-Lindau syndrome (VHL), succinate dehydrogenase complex - subunit D syndrome (SDHD), and patients treated with proton pump inhibitors (PPI).

Table 1. The clinical sensitivity of PPGL (PHEO or PGL) patients with concentrations of plasma free metanephrine (MN), plasma free normetanephrine (NMN) and plasma chromogranin A (CGA) determined before the adrenal operation.

Patients with pheochromocytoma or paraganglioma before adrenal surgery

\begin{tabular}{|c|c|c|c|c|c|c|c|c|c|c|c|}
\hline \multirow{2}{*}{ Phenotype } & \multirow{2}{*}{ Syndrome } & \multirow[t]{2}{*}{$\mathbf{n}$} & \multicolumn{3}{|c|}{$\begin{array}{c}\text { MN (ng/l) } \\
\text { Cut-off value=100 ng/l }\end{array}$} & \multicolumn{3}{|c|}{$\begin{array}{c}\text { NMN (ng/l) } \\
\text { Cut-off value=170 ng/l }\end{array}$} & \multicolumn{3}{|c|}{$\begin{array}{c}\text { CGA }(\mu \mathrm{g} / \mathrm{l}) \\
\text { Cut-off value }=150 \mu \mathrm{g} / \mathrm{l}\end{array}$} \\
\hline & & & Mean & SD & Range & Mean & SD & Range & Mean & SD & Range \\
\hline \multirow{4}{*}{ Adrenergic } & PHEO & 23 & 844 & 724 & $101-2877$ & 1318 & 2376 & $21-11368$ & 839 & 599 & $71-1779$ \\
\hline & $\begin{array}{l}\text { PHEO } \\
\text { MEN } 2 A+M T C\end{array}$ & 4 & 631 & 394 & $132-1041$ & 3290 & 2951 & $63-7096$ & 1016 & 399 & $444-1333$ \\
\hline & $\begin{array}{l}\text { PHEO } \\
\text { MEN2B+MTC }\end{array}$ & 1 & 442 & - & - & 151 & - & - & 497 & - & - \\
\hline & $P H E O-N F 1$ & 2 & 669 & 668 & 196-1141 & 275 & 219 & $121-430$ & 294 & 21 & 279-309 \\
\hline \multirow{4}{*}{ Noradrenergic } & PHEO & 13 & 34 & 23 & $11-84$ & 1102 & 1410 & $227-5006$ & 618 & 525 & $184-2036$ \\
\hline & $P H E O-V H L$ & 3 & 26 & 30 & $2-60$ & 1355 & 953 & $431-2335$ & 244 & 127 & $123-377$ \\
\hline & $P G L$ & 8 & 32 & 21 & $5-71$ & 424 & 288 & $108 *-952$ & 341 & 286 & $103-939$ \\
\hline & $P G L-S D H D$ & 1 & 15 & - & - & 790 & - & - & 469 & - & - \\
\hline \multicolumn{2}{|c|}{ CLINICAL SENSITIVITY } & 55 & \multicolumn{2}{|c|}{$\mathrm{MN}=55 \%$} & \multicolumn{2}{|c|}{ NMN $=80 \%$} & \multicolumn{2}{|c|}{$\mathrm{MN}+\mathrm{NMN}=96 \%$} & \multicolumn{3}{|c|}{ CGA $=93 \%$} \\
\hline
\end{tabular}

Abbreviations: pheochromocytoma (PHEO), paraganglioma (PGL), multiple endocrine neoplasia (MEN), medullary thyroid cancer (MTC), von Recklinghausen neurofibromatosis type 1 (NF1), von Hippel-Lindau syndrome (VHL), and succinate dehydrogenase complex subunit D syndrome (SDHD). 


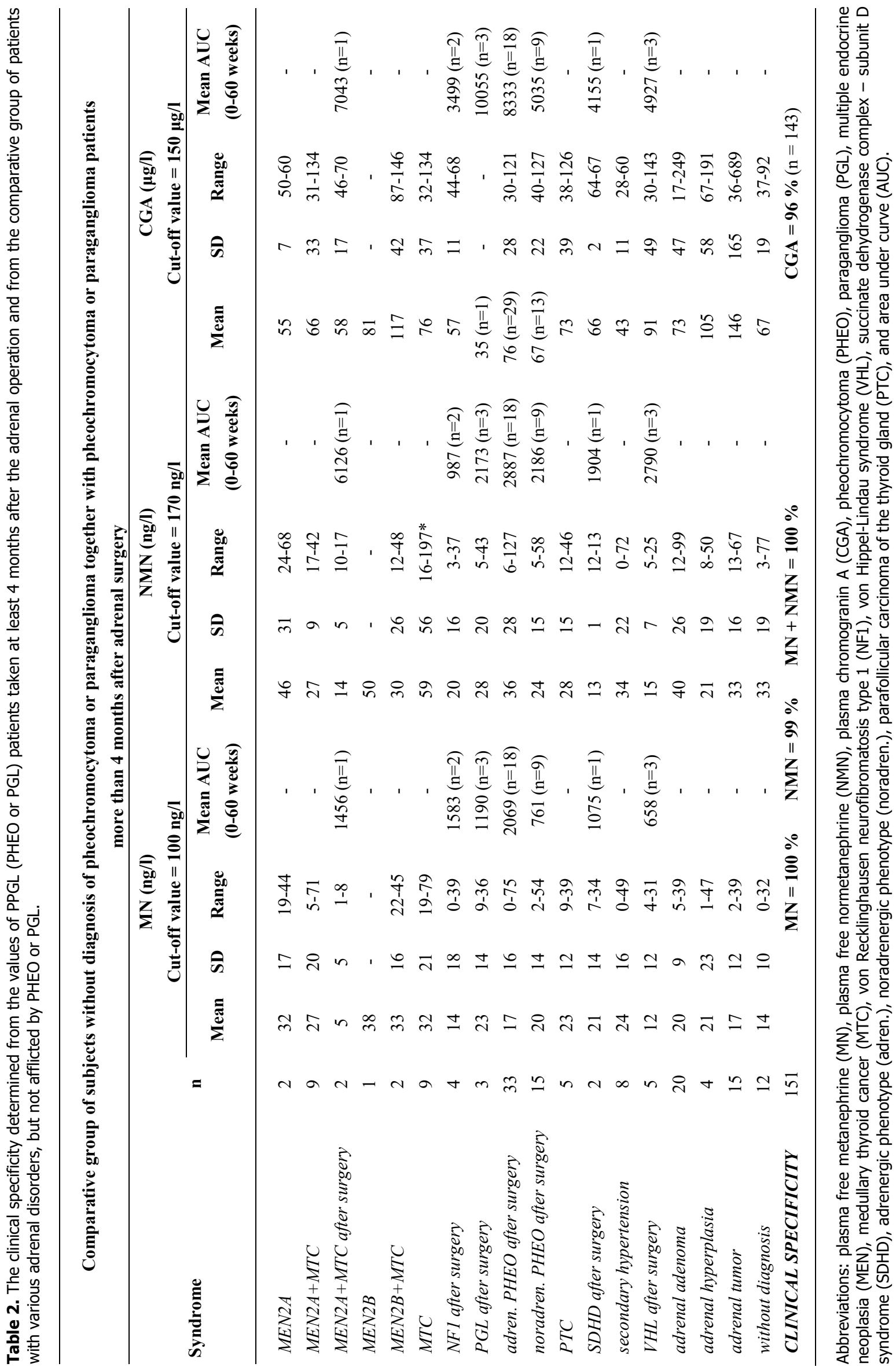


The mass of the operated tumor correlated to the MN, NMN and CGA concentration according to the equations:

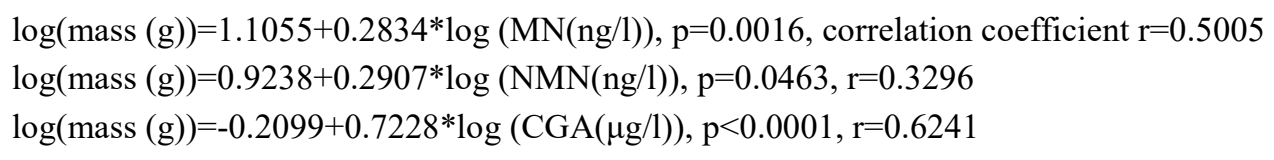

PASS scores (Thompson 2002) correlated with concentrations MN, NMN and CGA according to equations:

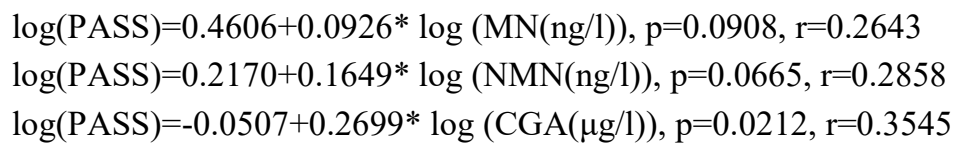

Correlations between the ascertained AUC (area under curve) logarithmic values and MN, NMN and CGA logarithmic values were sought. A statistically important correlation was only found in the case of NMN and was governed by the following equation:

$\log (\operatorname{mass}(\mathrm{g}))=-0.8480+0.7579 * \log (\operatorname{AUC}(\mathrm{NMN}(\mathrm{ng} / \mathrm{l}))), \mathrm{p}=0.0062, \mathrm{r}=0.4662$

\section{Discussion}

Although PHEO or PGL is a rare tumor of chromaffin cells, it has serious health consequences on the health of afflicted patients. Its familiar occurrence in individuals with a genetic predisposition is even common in young people and it often consists of a bilateral tumor with aggressive biological behavior (Lenders et al. 2014). Unlike the determination of $\mathrm{MN}$ or $\mathrm{NMN}$, the determination of CGA is not influenced by hypertensive drugs, substances and activities affecting biosynthesis and the secretion of catecholamines, but the determination of CGA in administering protein pump inhibitors and in patients with severe renal insufficiency is limited.

In the case of $\mathrm{MN}$, the predictive value of the test failed from a clinical sensitivity standpoint for patients with noradrenergic phenotype. By contrast, there can be a problem with NMN for patients with adrenergic phenotype. In the case of PPGL patients, it is therefore very important to conduct a parallel determination of both $\mathrm{MN}$ and NMN. In the monitored group, increased values of CGA, MN and NMN were only found in connection with the PPGL diagnosis, while for patients with MEN syndrome or MTC without the presence of PHEO or PGL, the values were within the reference range.

The advantage of the immunoassay approach is that these methods are common in a clinical-biochemical laboratory and do not require additional expensive instrumentation. Limitations are given by the immunoassay principle in which, owing to interference, the immunological quantity does not have to correspond to the biological activity.

The result of the modeling enabled the course of change to be predicted, provided information on the used reference ranges and enabled a determination of the mean period of the return of MN, NMN and CGA to the normal reference range following the adrenal gland operation. The AUC (area under curve) given in Table 2 provides information on the overall biosynthesis of $\mathrm{MN}, \mathrm{NMN}$ and CGA during the monitored period. The AUC values should be further examined from a clinical standpoint.

We can conclude that both the combination plasma MN/NMN and plasma CGA as determined by radioimmunoassays, which are simple without the necessity of special laboratory material, are an effective markers of PPGLs. Plasma CGA exerts association to malignity and all markers are associated with tumor mass.

\section{Conflict of Interest}

There is no conflict of interest.

\section{Acknowledgements}

This work was supported by grants IGA MZ CR NT/12336-4, the MEYS CR (OP RDE, Excellent research - ENDO.CZ) and $\mathrm{MH} \mathrm{CZ} \mathrm{-} \mathrm{DRO} \mathrm{(Institute} \mathrm{of}$ Endocrinology - EÚ, 00023761). 


\section{References}

ADAWAY JE, PEITZSCH M, KEEVIL BG: A novel method for the measurement of plasma metanephrines using online solid phase extraction-liquid chromatography tandem mass spectrometry. Ann Clin Biochem 52: 361-369, 2015.

ANDERSEN KF, ALTAF R, KRARUP-HANSEN A, KROMANN-ANDERSEN B, HORN T, CHRISTENSEN NJ, HENDEL HW: Malignant pheochromocytomas and paragangliomas - the importance of a multidisciplinary approach. Cancer Treat Rev 37: 111-119, 2011.

BILEK R, SAFARIK L, CIPROVA V, VLCEK P, LISA L: Chromogranin A, a member of neuroendocrine secretory proteins as a selective marker for laboratory diagnosis of pheochromocytoma. Physiol Res 57 (Suppl 1): S171-S179, 2008.

BRAIN KL, KAY J, SHINE B: Measurement of urinary metanephrines to screen for pheochromocytoma in an unselected hospital referral population. Clin Chem 52: 2060-2064, 2006.

BUSNARDO B, NACAMULLI D, ZAMBONIN L, MIAN C, PICCOLO M, GIRELLI ME: Restricted intraindividual urinary iodine concentration variability in nonfasting subjects. Eur J Clin Nutr 60: 421-425, 2006.

CHEN H, SIPPEL RS, O'DORISIO MS, VINIK AI, LLOYD RV, PACAK K: The North American Neuroendocrine Tumor Society consensus guideline for the diagnosis and management of neuroendocrine tumors: pheochromocytoma, paraganglioma, and medullary thyroid cancer. Pancreas 39: 775-783, 2010.

D'AMICO MA, GHINASSI B, IZZICUPO P, MANZOLI L, DI BALDASSARRE A: Biological function and clinical relevance of chromogranin A and derived peptides. Endocr Connect 3: R45-R54, 2014.

DARR R, PAMPORAKI C, PEITZSCH M, MIEHLE K, PREJBISZ A, PECZKOWSKA M, WEISMANN D, BEUSCHLEIN F, SINNOTT R, BORNSTEIN SR, NEUMANN HP, JANUSZEWICZ A, LENDERS J, EISENHOFER G: Biochemical diagnosis of phaeochromocytoma using plasma-free normetanephrine, metanephrine and methoxytyramine: importance of supine sampling under fasting conditions. Clin Endocrinol (Oxf) 80: 478-486, 2014.

D'HERBOMEZ M, GOUZE V, HUGLO D, NOCAUDIE M, PATTOU F, PROYE C, WEMEAU JL, MARCHANDISE X: Chromogranin A assay and (131)I-MIBG scintigraphy for diagnosis and follow-up of pheochromocytoma. J Nucl Med 42: 993-997, 2001.

D'HERBOMEZ M, FORZY G, BAUTERS C, TIERNY C, PIGNY P, CARNAILLE B, PATTOU F, WEMEAU JL, ROUAIX N: An analysis of the biochemical diagnosis of 66 pheochromocytomas. Eur J Endocrinol 156: 569-575, 2007.

D'HERBOMEZ M, DO CAO C, VEZZOSI D, BORZON-CHASOT F, BAUDIN E: Chromogranin A assay in clinical practice. Ann Endocrinol (Paris) 71: 274-280, 2010.

EISENHOFER G, PEITZSCH M: Laboratory evaluation of pheochromocytoma and paraganglioma. Clin Chem 60: 1486-1499, 2014.

EISENHOFER G, LENDERS JW, TIMMERS H, MANNELLI M, GREBE SK, HOFBAUER LC, BORNSTEIN SR, TIEBEL O, ADAMS K, BRATSLAVSKY G, LINEHAN WM, PACAK K: Measurements of plasma methoxytyramine, normetanephrine, and metanephrine as discriminators of different hereditary forms of pheochromocytoma. Clin Chem 57: 411-420, 2011.

EISENHOFER G, LENDERS JW, SIEGERT G, BORNSTEIN SR, FRIBERG P, MILOSEVIC D, MANNELLI M, LINEHAN WM, ADAMS K, TIMMERS HJ, PACAK K: Plasma methoxytyramine: a novel biomarker of metastatic pheochromocytoma and paraganglioma in relation to established risk factors of tumour size, location and SDHB mutation status. Eur J Cancer 48: 1739-1749, 2012.

EISENHOFER G, LATTKE P, HERBERG M, SIEGERT G, QIN N, DARR R, HOYER J, VILLRINGER A, PREJBISZ A, JANUSZEWICZ A, REMALEY A, MARTUCCI V, PACAK K, ROSS HA, SWEEP FC, LENDERS JW: Reference intervals for plasma free metanephrines with an age adjustment for normetanephrine for optimized laboratory testing of phaeochromocytoma. Ann Clin Biochem 50: 62-69, 2013.

ESTENSEN ME, HOGNESTAD A, SYVERSEN U, SQUIRE I, NG L, KJEKSHUS J, DICKSTEIN K, OMLAND T: Prognostic value of plasma chromogranin A levels in patients with complicated myocardial infarction. Am Heart J 152: 927.e1-927.e6, 2006. 
FLIEDNER SM, LEHNERT H, PACAK K: Metastatic paraganglioma. Semin Oncol 37: 627-637, 2010.

GIOVANELLA L, SQUIN N, GHELFO A, CERIANI L: Chromogranin A immunoradiometric assay in diagnosis of pheochromocytoma: comparison with plasma metanephrines and 123I-MIBG scan. Q J Nucl Med Mol Imaging 50: 344-347, 2006.

GIOVINAZZO F, SCHIMMACK S, SVEJDA B, ALAIMO D, PFRAGNER R, MODLIN I, KIDD M: Chromogranin $\mathrm{A}$ and its fragments as regulators of small intestinal neuroendocrine neoplasm proliferation. PLoS One 8: e81111, 2013.

GREENBAUM A, CHARTIER T: Numerical Methods: Design, Analysis, and Computer Implementation of Algorithms. Princeton University Press, Princeton, 2012, pp 185-189.

GROUZMANN E, TSCHOPP O, TRIPONEZ F, MATTER M, BILZ S, BRANDLE M, DRECHSER T, SIGRIST S, ZULEWSKI H, HENZEN C, FISCHLI S, ABID K: Catecholamine metabolism in paraganglioma and pheochromocytoma: similar tumors in different sites? PLoS One 10: e0125426, 2015.

JANSSON AM, ROSJO H, OMLAND T, KARLSSON T, HARTFORD M, FLYVBJERG A, CAIDAHL K: Prognostic value of circulating chromogranin A levels in acute coronary syndromes. Eur Heart J 30: 25-32, 2009.

KORSE CM, MULLER M, TAAL BG: Discontinuation of proton pump inhibitors during assessment of chromogranin A levels in patients with neuroendocrine tumours. Br J Cancer 105: 1173-1175, 2011.

LAWRENCE B, GUSTAFSSON BI, KIDD M, PAVEL M, SVEJDA B, MODLIN IM: The clinical relevance of chromogranin A as a biomarker for gastroenteropancreatic neuroendocrine tumors. Endocrinol Metab Clin North Am 40: 111-134, viii, 2011.

LENDERS JW, EISENHOFER G, MANNELLI M, PACAK K: Phaeochromocytoma. Lancet 366: 665-675, 2005.

LENDERS JW, DUH QY, EISENHOFER G, GIMENEZ-ROQUEPLO AP, GREBE SK, MURAD MH, NARUSE M, PACAK K, YOUNG WF JR: Pheochromocytoma and paraganglioma: an endocrine society clinical practice guideline. J Clin Endocrinol Metab 99: 1915-1942, 2014.

MALAGUARNERA M, VACANTE M, FICHERA R, CAPPELLANI A, CRISTALDI E, MOTTA M: Chromogranin A (CgA) serum level as a marker of progression in hepatocellular carcinoma (HCC) of elderly patients. Arch Gerontol Geriatr 51: 81-85, 2010.

MAZZAGLIA PJ: Hereditary pheochromocytoma and paraganglioma. J Surg Oncol 106: 580-585, 2012.

MOSLI HH, DENNIS A, KOCHA W, ASHER LJ, VAN UUM SH: Effect of short-term proton pump inhibitor treatment and its discontinuation on chromogranin A in healthy subjects. J Clin Endocrinol Metab 97: E1731-E1735, 2012.

O'CONNOR DT, PANDLAN MR, CARLTON E, CERVENKA JH, HSLAO RJ: Rapid radioimmunoassay of circulating chromogranin A: in vitro stability, exploration of the neuroendocrine character of neoplasia, and assessment of the effects of organ failure. Clin Chem 35: 1631-1637, 1989.

PAMPORAKI C, DARR R, BURSZTYN M, GLOCKNER S, BORNSTEIN SR, LENDERS JW, PACAK K, KRINNER A, EISENHOFER G: Plasma-free vs deconjugated metanephrines for diagnosis of phaeochromocytoma. Clin Endocrinol (Oxf) 79: 476-483, 2013.

PUSSARD E, CHAOUCH A, SAID T: Radioimmunoassay of free plasma metanephrines for the diagnosis of catecholamine-producing tumors. Clin Chem Lab Med 52: 437-444, 2014.

SZALAT A, FRAENKEL M, DOVINER V, SALMON A, GROSS DJ: Malignant pheochromocytoma: predictive factors of malignancy and clinical course in 16 patients at a single tertiary medical center. Endocrine 39: 160-166, 2011.

THOMPSON LD: Pheochromocytoma of the Adrenal gland Scaled Score (PASS) to separate benign from malignant neoplasms: a clinicopathologic and immunophenotypic study of 100 cases. Am J Surg Pathol 26: 551-566, 2002.

TISCHLER AS: Molecular and cellular biology of pheochromocytomas and extra-adrenal paragangliomas. Endocr Pathol 17: 321-328, 2006.

UNGER N, HINRICHS J, DEUTSCHBEIN T, SCHMIDT H, WALZ MK, MANN K, PETERSENN S: Plasma and urinary metanephrines determined by an enzyme immunoassay, but not serum chromogranin A for the diagnosis of pheochromocytoma in patients with adrenal mass. Exp Clin Endocrinol Diabetes 120: 494-500, 2012. 
VAN BERKEL A, LENDERS JW, TIMMERS HJ: Diagnosis of endocrine disease: Biochemical diagnosis of phaeochromocytoma and paraganglioma. Eur J Endocrinol 170: R109-R119, 2014.

WEISMANN D, PEITZSCH M, RAIDA A, PREJBISZ A, GOSK M, RIESTER A, WILLENBERG HS, KLEMM R, MANZ G, DEUTSCHBEIN T, KROISS M, DARR R, BIDLINGMAIER M, JANUSZEWICZ A, EISENHOFER G, FASSNACHT M: Measurements of plasma metanephrines by immunoassay vs liquid chromatography with tandem mass spectrometry for diagnosis of pheochromocytoma. Eur J Endocrinol 172: 251-260, 2015.

ZELINKA T, PETRAK O, TURKOVA H, HOLAJ R, STRAUCH B, KRSEK M, VRANKOVA AB, MUSIL Z, DUSKOVA J, KUBINYI J, MICHALSKY D, NOVAK K, WIDIMSKY J: High incidence of cardiovascular complications in pheochromocytoma. Horm Metab Res 44: 379-384, 2012.

ZUBER S, WESLEY R, PRODANOV T, EISENHOFER G, PACAK K, KANTOROVICH V: Clinical utility of chromogranin A in SDHx-related paragangliomas. Eur J Clin Invest 44: 365-371, 2014. 